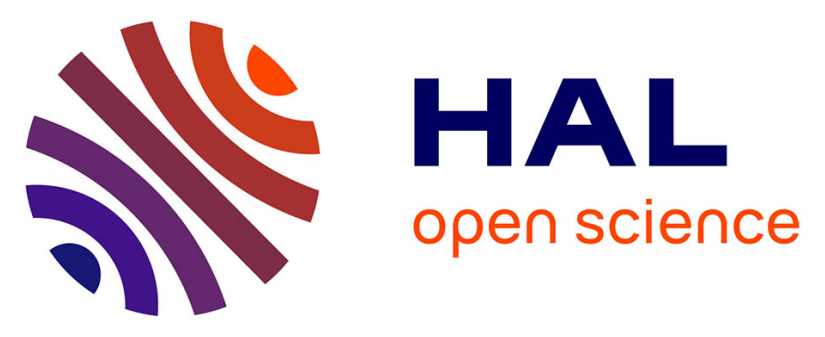

\title{
Palladium-catalyzed coupling of N-tosylhydrazones with ortho substituted aryl halides: synthesis of 4-arylchromenes and related heterocycles
}

\author{
Evelia Rasolofonjatovo, Bret Tréguier, Olivier Provot, Abdallah Hamze, \\ Estelle Morvan, Jean-Daniel Brion, Mouad Alami
}

\section{To cite this version:}

Evelia Rasolofonjatovo, Bret Tréguier, Olivier Provot, Abdallah Hamze, Estelle Morvan, et al.. Palladium-catalyzed coupling of N-tosylhydrazones with ortho substituted aryl halides: synthesis of 4-arylchromenes and related heterocycles. Tetrahedron Letters, 2011, 52 (9), pp.1036-1040. 10.1016/j.tetlet.2010.12.093 . hal-02394469

\section{HAL Id: hal-02394469 \\ https://hal.science/hal-02394469}

Submitted on 4 Dec 2019

HAL is a multi-disciplinary open access archive for the deposit and dissemination of scientific research documents, whether they are published or not. The documents may come from teaching and research institutions in France or abroad, or from public or private research centers.
L'archive ouverte pluridisciplinaire HAL, est destinée au dépôt et à la diffusion de documents scientifiques de niveau recherche, publiés ou non, émanant des établissements d'enseignement et de recherche français ou étrangers, des laboratoires publics ou privés. 


\section{Graphical Abstract}

To create your abstract, type over the instructions in the template box below.

Fonts or abstract dimensions should not be changed or altered.

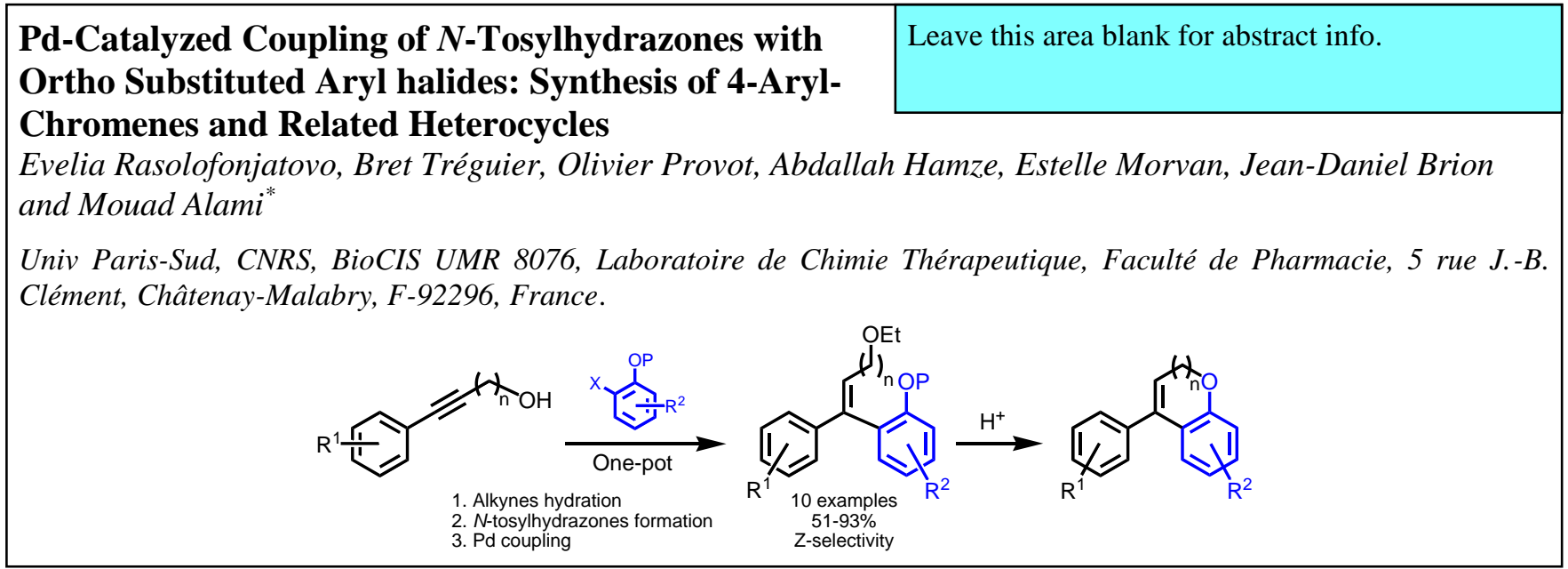

Keywords: palladium; $N$-tosylhydrazone; alkyne hydration; trisubstituted olefin; cyclization; $p$-toluenesulfonic acid; chromene; thiochromene; dihydrobenzo-oxepine. 


\title{
Palladium-Catalyzed Coupling of $N$-Tosylhydrazones with Ortho Substituted Aryl Halides: Synthesis of 4-Arylchromenes and Related Heterocycles
}

\author{
Evelia Rasolofonjatovo, Bret Tréguier, Olivier Provot, Abdallah Hamze, Estelle Morvan, \\ Jean-Daniel Brion and Mouad Alami* \\ Univ Paris-Sud, BioCIS- UMR 8076, Laboratoire de Chimie Thérapeutique, Faculté de Pharmacie, rue J.B. Clément Châtenay-Malabry, \\ F-92296 France
}

\begin{abstract}
A convenient and efficient procedure for the synthesis of 4-arylchromenes, thiochromenes and related heterocycles via a four step sequence has been developed. The first three steps which involve hydration of alkynes, hydrazones formation and their Pd-coupling with ortho substituted aryl halides, furnished $Z$-trisubstituted olefins without any purification of the intermediates generated in each stage. These latter proved to be suitable precursors, in the last step, for the synthesis of the desired heterocycles of biological interest. (C) 2019 Elsevier Science. All rights reserved
\end{abstract}

In an ongoing medicinal chemistry program directed toward the synthesis of anticancer ${ }^{1}$ substances and particularly antimitotic agents, ${ }^{2}$ we recently found that isocombretastatin A-4 (isoCA-4), ${ }^{3}$ the third and "forgotten" structural isomer of the natural product, displayed biological activities comparable to that of CA-4 (Figure 1). This substance having a 1,1-diarylethylene scaffold $^{4}$ is easy to synthesize without the need to control the olefin geometry. Bioisosteric replacement was successfully extended to compounds $\mathbf{1}$ and $\mathbf{2}$ having a trior tetra-substituted double bond. ${ }^{3 a, 5}$ In this article we reconfigured the substitution pattern around the double by the preparation of 4-arylchromenes of type $\mathbf{3}$, that could be considered as constraint analogues of isoCA-4, in which the double bond is tri-substituted (Scheme 1).

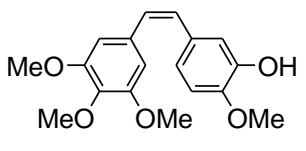

CA-4<smiles>COc1ccc(C(=CC#N)c2cc(OC)c(OC)c(OC)c2)cc1O</smiles><smiles>COc1ccc(C(=C(F)F)c2cc(OC)c(OC)c(OC)c2)cc1O</smiles>

Figure 1. Structure of CA-4, isoCA-4 and synthetic tubulin assembly inhibitors $\mathbf{1}$ and $\mathbf{2}$.<smiles>C=C(c1ccc(OC)c(O)c1)c1ccc(OC)c(OC)c1</smiles>

A survey of the literature showed that few routes have been developed for the preparation of 4-arylchromenes $\mathbf{3}$, including the coupling of 4-OTf-chromene derivatives with arylboronic acids, ${ }^{6}$ a reaction of 4-methoxycarbonylchromane-3-one with aryllead triacetates, ${ }^{7}$ ring-closing metathesis ${ }^{8}$ and so on. ${ }^{9}$

The strategy envisioned herein to prepare the target chromenes $\mathbf{3}$ involves a four step-sequence based on regioselective hydration of alkynes ${ }^{10} \mathbf{7}$ or $\mathbf{8}, \quad \mathrm{N}$ tosylhydrazones $\mathbf{5}$ and $\mathbf{6}$ formation, followed by their $\mathrm{Pd}-$ coupling reaction ${ }^{3 \mathrm{a}, 11}$ with appropriate aryl halides (path a or $b$, Scheme 1) and subsequent $O$-cylization.

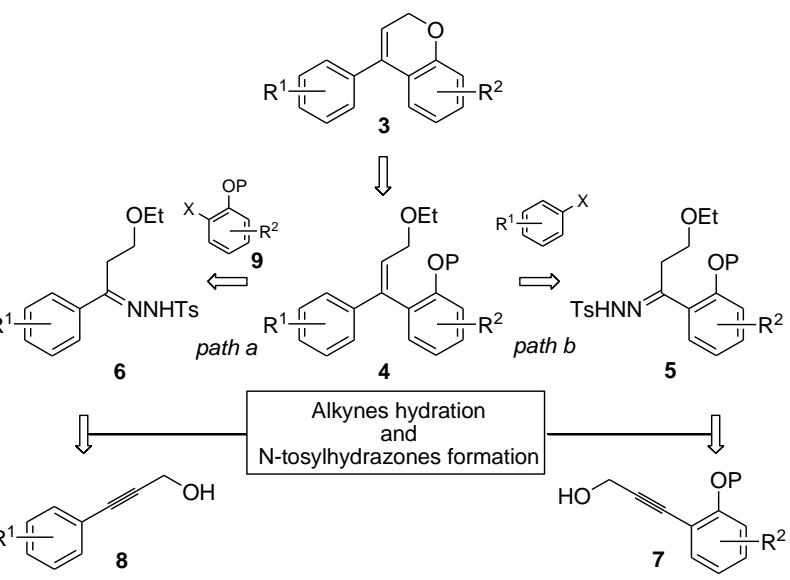

Scheme 1. Retrosynthetic analysis of targeted 4arylchromene derivatives $\mathbf{3}$.

* Corresponding author. Tel.: +33-1-46.83.58.87; fax: +33-1-46.83.58.28; e-mail: mouad.alami@u-psud.fr 
Previously we reported the hydration of internal alkynes, in EtOH under a catalytic amount of $p$-toluenesulfonic acid (PTSA). Under this environmentally friendly procedure, aliphatic arylalkynes were regioselectively converted into their corresponding carbonyl compounds according to Markovnikov's rules. ${ }^{12}$ Because the reactions conditions for the hydration of arylalkynes and the tosylhydrazones formation from the corresponding carbonyl compounds are similar (cat. PTSA in EtOH), we decided to investigate whether it might be possible to carry in a one-pot fashion the sequential hydration of $\mathbf{8}$, in situ $N$-tosylhydrazones $\mathbf{6}$ formation, and palladiumcatalyzed coupling reaction with ortho substituted aryl halides according to path a (Scheme 1). Herein we reported the results of this study and demonstrated that the resulting olefins $\mathbf{4}$ are suitable precursors of 4arylchromenes $\mathbf{3}$ and related heterocycles.

At the outset of this work, the one-pot synthesis of $\mathbf{4 a}$ (Table 1, entry 1) was first examined from alkyne $\mathbf{8 a}$, easily available by Sonogashira-Linstrumelle coupling reaction. ${ }^{13} \mathrm{We}$ then decided to achieve this transformation in a sequential way by heating $8 \mathbf{a}$ in $\mathrm{EtOH}$ in the presence of PTSA (20 mol\%) in a first step then, by introducing $N$ tosylhydrazine in a second step, and finally by coupling the in situ obtained hydrazone with ortho substituted aryl iodide 9a using $\mathrm{PdCl}_{2}(\mathrm{MeCN})_{2} / \mathrm{Xphos}$ as the catalytic system. ${ }^{14}$ Under these conditions, we were pleased to observe that this sequential process worked very well and provided the desired tri-substitued olefin $4 \mathbf{a}$ in a $68 \%$ overall yield (Entry 1, Table 1). ${ }^{15}$ One can note that 4a was isolated with a marked $Z$-selectivity of $>9: 1$. To the best of our knowledge, only one example with such $Z$ preference was reported very recently by Barluenga et al. ${ }^{16}$ in the synthesis of a 2-arylacrylate, readily obtained from the coupling of a functionalized hydrazone with an ortho substituted aryl bromide. On the basis of these observations, we reasoned that this co-operative ortho effect could be exploited to give $Z$-trisubstitued olefins 4 with high diastereoisomeric ratio $(\mathrm{dr})$.

In seeking a further enhancement of $Z$-selectivity, we next applied the one-pot three-step sequence to ortho substituted aryl halides 9b-f (entries 2-6). In most cases studied, an improvement in $\operatorname{dr}(Z / E$ from $>9: 1$ to 100:0) was observed in comparison to the aforementioned result obtained in entry 1. As expected, the process can be accomplished also with other aliphatic arylalkynes (Entries 7-10). Alkyne 8b with a butynol chain (Entries 79), provided olefins 4g-i with good overall yields (55$71 \%)$. Finally alkyne 8c having an $n$-pentyl chain was also efficiently transformed into olefin $\mathbf{4 j}$ as a single $Z$ isomer in a $51 \%$ overall yield (entry 10). Altogether, these results (entries 7-10) clearly demonstrated that the substituent attached to the triple bond had no deleterious effect on the $Z / E$ distribution, and olefins $\mathbf{4 g}$-j were isolated with a total $Z$-preference.

In the coupling step of $N$-tosylhydrazones with aryl halides, a migratory insertion of Pd carbene species has been suggested as the key step. ${ }^{3 a}$ According to this reaction mechanism, coupling of $N$-tosylhydrazone $\mathbf{6 a}$ with ortho iodoanisole (path a, Scheme 2) would form Pd carbene species I, whereas the reaction of ortho methoxy $N$-tosylhydrazone 5a with 4-iodoanisole would furnish II (path b, Scheme 2). These intermediates species I and II should evolve according to the migratory insertion of the anisyl ring to give the same alkylpalladium complex III. Further $\beta$-hydride elimination on III would give olefin 4d, logically with the same diastereoisomeric ratio. To check this hypothesis, we carry out the coupling of ortho methoxy $N$-tosylhydrazone 5a with 4-iodoanisole according to path $b$ (Scheme 2). Although 4d was formed in a low $18 \%$ yield, a similar dr $(Z / E=$ ca. 19:1) was observed and may be compare to the one obtained according to path a (Entry 4, Table 1).

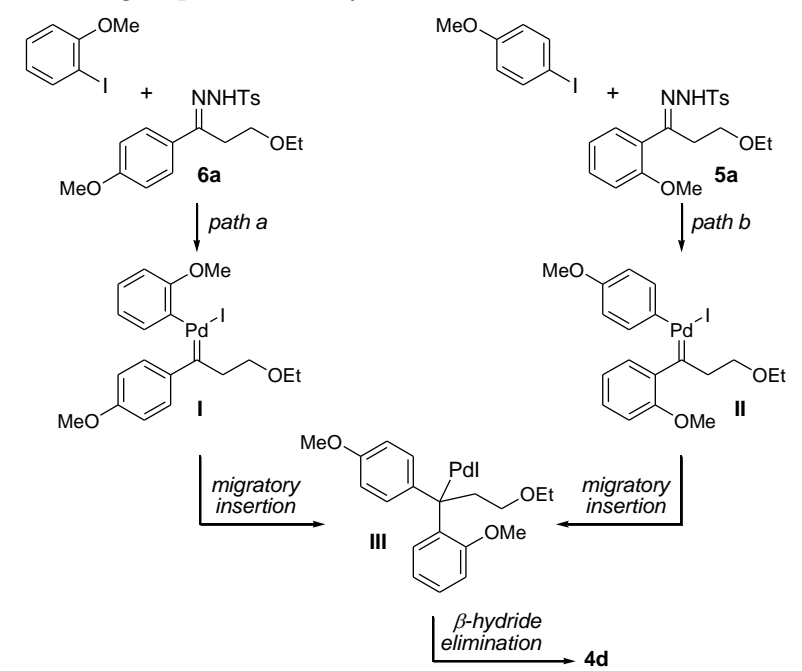

Scheme 2. Palladium-catalyzed formation of olefin 4d according paths $a$ and $b$.

Altogether, the results depicted in Table 1 show that the use of ortho substituted aryl halides as electrophilic partners in the coupling with $N$-tosylhydrazones provides mainly to exclusively olefins $\mathbf{4}$ with a $Z$-configuration, even if the exact origin of this diastereoselectivity remains unclear.

To achieve our goal, we next treated olefins having an ortho OMOM substituent $\mathbf{4 a}, \mathbf{4 f}$ and $\mathbf{4 g}$ in acidic media. Thus, when heating $\mathbf{4 a}$ and $\mathbf{4 f}$ with PTSA in EtOH we were delighted to observe rapidly the formation of the desired 4-arylchromene derivatives 3a,b in excellent yields (Scheme 3). ${ }^{17}$ With substrate $\mathbf{4 g}$, TfOH was found to be superior than PTSA, and achieve the cyclization reaction efficiently providing the expected 5-aryl-2,3dihydrobenzo $[b]$ oxepine $\mathbf{1 0}$.

To extend the scope of this transformation, we finally examined the cyclization of olefin $\mathbf{4 b}$ having an ortho methylthio substituent. We were pleased to find that upon heating in the presence of $\mathrm{TfOH}, \mathbf{4 b}$ cyclized to afford after hydrolysis the arylthiochromenylium hydroxide $\mathbf{1 1}$ in good yield $(85 \%)$. If the cyclization reaction of $\mathbf{4 b}$ was conducted in the presence of $\mathrm{TfOH}$ followed by addition of $\mathrm{Et}_{3} \mathrm{~N}$, the expected 1-arylthiochromene 12 was isolated in a $78 \%$ overall yield (Scheme 3 ). 
Table 1. Stereoselective synthesis of trisubstituted olefins 4 from arylalkynes 8 through a one-pot three step sequence based on hydration of $\mathbf{8}, \mathrm{N}$-tosylhydrazone formation and Pd-catalyzed coupling reaction with ortho substituted aryl halides.
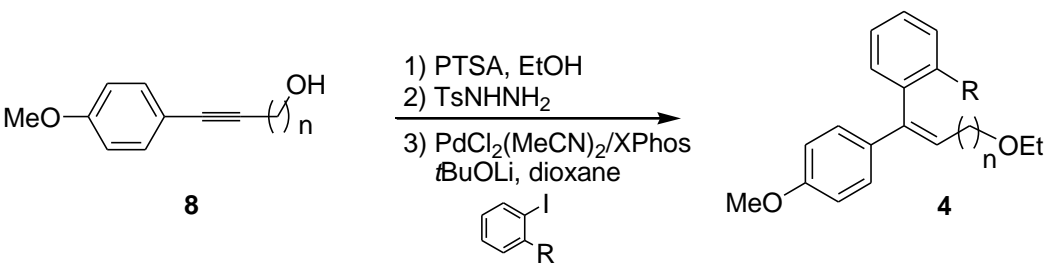

\begin{tabular}{|c|c|c|c|c|c|c|}
\hline Entry & Alkyne 8 & Aryl halide 9 & Product Z-4 & & Yield $(\%)^{\mathrm{a}}$ & $Z: E$ Ratio $^{\mathrm{b}}$ \\
\hline 1 & $8 \mathbf{a}$ & & & $4 a$ & 68 & 9:1 \\
\hline 2 & $8 \mathbf{a}$ & & & $4 b$ & 93 & 100:0 \\
\hline 3 & $8 \mathbf{a}$ & & & $4 c$ & 80 & 100:0 \\
\hline 4 & $8 \mathbf{a}$ & & & $4 d$ & 77 & $>9: 1^{c}$ \\
\hline 5 & $8 \mathbf{a}$ & & & $4 e$ & 68 & 19:1 \\
\hline 6 & $8 \mathbf{a}$ & & & $4 f$ & 57 & $>19: 1$ \\
\hline 7 & & & & $4 g$ & 71 & $19: 1$ \\
\hline 8 & $8 b$ & & & $4 h$ & 58 & 100:0 \\
\hline 9 & $8 b$ & ) & & $4 i$ & 55 & 100:0 \\
\hline 10 & $8 c$ & $c$ & & $4 j$ & 51 & 100:0 \\
\hline
\end{tabular}

a Overall isolated yield based on alkyne 8. All reactions were performed according to general procedure; see: ref.15.

${ }^{\mathrm{b}}$ Ratio of stereoisomer $E$ and $Z$ determined in the crude reaction mixture by ${ }^{1} \mathrm{H}$ NMR. The $Z$-configuration of all compounds described herein was assigned by NOESY experiments.

${ }^{c}$ A low diastereoisomeric Z-preference $(\mathrm{dr}=1.5: 1$, yield $=78 \%)$ was obtained when using 3-iodoanisole instead of 2-iodoanisole. 


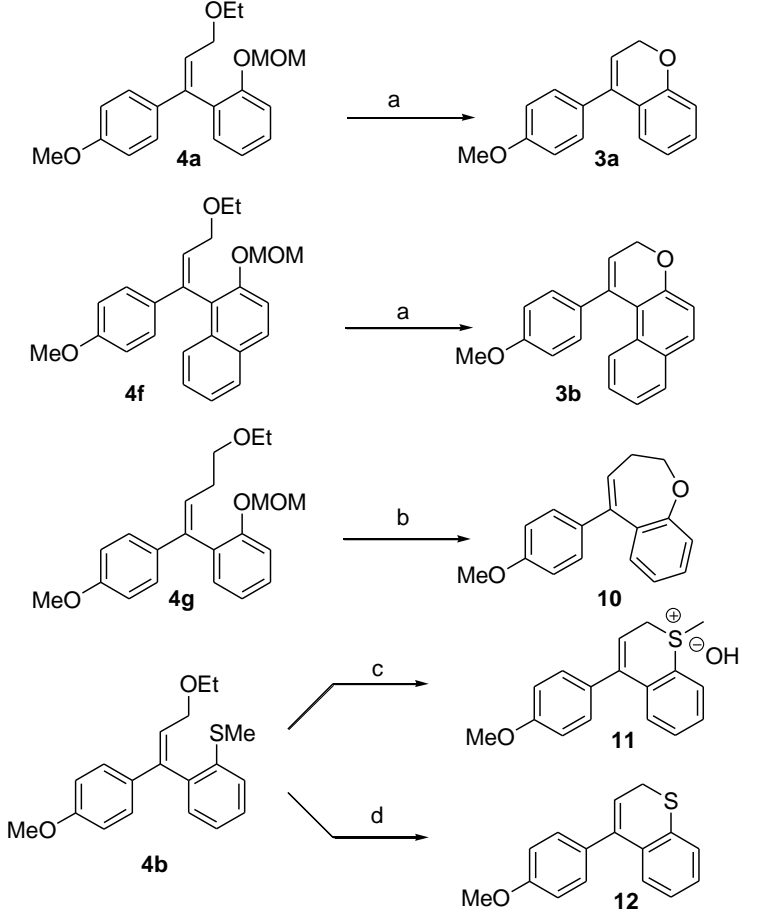

Scheme 3. Reagents and conditions: (a) PTSA (3 equiv.) EtOH, reflux, 1 h, 3a: 98\%, 3b: 78\%. (b) TfOH cat. dioxane, reflux, $15 \mathrm{~h}, 62 \%$. (c) $\mathrm{TfOH}$ cat. $\mathrm{CH}_{2} \mathrm{Cl}_{2}, \mathrm{rt}, 30$ min., $85 \%$ (d) (i) TfOH cat. $\mathrm{CH}_{2} \mathrm{Cl}_{2}, 20{ }^{\circ} \mathrm{C}, 30 \mathrm{~min}$; (ii) $\mathrm{Et}_{3} \mathrm{~N}$ (2 equiv.) $\mathrm{EtOH}, 20{ }^{\circ} \mathrm{C}, 78 \%$.

In summary, we have described a convenient sequence to 4-arylchromenes and related heterocycles. This protocol is based on the one-pot regioselective hydration of alkynes, $N$-tosylhydrazones formation, followed by their palladium-catalyzed coupling with aryl halides to form trisubstituted olefins with $Z$-selectivity. Further Brönsted acid-mediated cylization provided the desired heterocycles. This process is very convenient and efficient because it significantly reduced reaction times and tedious procedures such as work-up and purification at each step. Reaction is general with respect to alkyne and ortho substituted aryl halides. Good yields, convenient isolation of the targeted heterocycles are the distinct characteristics of the developed protocol. Studies are currently under way for the synthesis of heterocycles related to isoCA-4 and will reported in due course.

Acknowledgments. The CNRS is gratefully acknowledged for financial support of this research. We thank The MRES for a doctoral fellowship to M.J. and ICSN for a doctoral fellowship to B.T.

\section{References}

1 (a) Le Bras, G.; Radanyi, C.; Peyrat, J.-F.; Brion, J.-D.; Alami, M.; Marsaud, V.; Stella, B.; Renoir, J. M. J. Med. Chem. 2007, 50, 6189. (b) Radanyi, C.; Le Bras, G.; Messaoudi, S.; Bouclier, C.; Peyrat, J.-F.; Brion, J.-D.; Marsaud, V.; Renoir, J. M.; Alami, M. Bioorg. Med. Chem. Lett. 2008, 18, 2495.

2 (a) Mousset, C.; Giraud, A.; Provot, O.; Hamze, A.; Bignon, J.; Liu, J. M.; Thoret, S.; Dubois, J.; Brion, J.-D.; Alami, M. Bioorg. Med. Chem. Lett. 2008, 18, 3266; (b) Mousset, C.; Provot, O.; Hamze, A.; Bignon, J.; Brion, J.-D.; Alami, M. Tetrahedron 2008, 64, 4287. (c)
Provot, O.; Giraud, A.; Peyrat, J.-F.; Alami, M.; Brion, J.-D. Tetrahedron Lett. 2005, 46, 8547.

3 (a) Messaoudi, S.; Treguier, B.; Hamze, A.; Provot, O.; Peyrat, J.F.; De Losada, J. R.; Liu, J. M.; Bignon, J.; Wdzieczak-Bakala, J.; Thoret, S.; Dubois, J.; Brion, J.-D.; Alami, M. J. Med. Chem. 2009, 52, 4538. (b) Hamze, A.; Giraud, A.; Messaoudi, S.; Provot, O.; Peyrat, J.-F.; Bignon, J.; Liu, J. M.; Wdzieczak-Bakala, J.; Thoret, S.; Dubois, J.; Brion, J.-D.; Alami, M. ChemMedChem 2009, 4, 1912.

4 Hamze, A.; Provot, O.; Brion, J. D.; Alami, M. J. Org. Chem. 2007, 72,3868 .

5 (a) Brachet, E.; Hamze, A.; Peyrat, J. F.; Brion, J. D.; Alami, M. Org. Lett. 2010, 12, 4042. (b) Rasolofonjatovo, E.; Provot, O.; Hamze, A.; Bignon, J.; Thoret, S.; Brion, J. D.; Alami, M. Eur. J. Med. Chem. 2010, 45, 3617.

6 (a) Eguchi, T.; Hoshino, Y.; Ayame, A. Bull. Chem. Soc. Jpn. 2002, 75, 581. (b) Kinoyama, I.; Miyamoto, S.; Miyazaki, T.; Koganemaru, Y.; Kawamoto, Y.; Shiraishi, N.; Hoshii, H.; Kuroda, A.; Yamazaki, M.; Yasuda, M.; Mizuno, H. Eur. Patent, 2010, EP 2177505A1.

7 Donnelly, D. M. X.; Finet, J.-P.; Guiry, P. J.; Nesbitt, K. Tetrahedron 2001, 57, 413.

8 Li, S.-R.; Chen, L.-Y.; Tsai, J.-C.; Tzeng, J.-Y.; Tsai, I.-L.; Wang, E.-C. Tetrahedron Lett. 2007, 48, 2139.

9 (a) Foroumadi, A.; Samzadeh-Kermani, A.; Emami, S.; Dehghan, G.; Sorkhi, M.; Arabsorkhi, F.; Heidari, M. R.; Abdollahi, M.; Shafiee, A. Bioorg. Med. Chem. Lett. 2007, 17, 6764; (b) Mukerjee, S. K.; Saroja, T.; Seshadri, T. R. Tetrahedron 1971, 27, 799; (c) Pinard, E.; Gaudry, M.; Hénot, F.; Thellend, A. Tetrahedron Lett. 1998, 39, 2739. (d) Whitehead, A.; Moore, J. D.; Hanson, P. R. Tetrahedron Lett. 2003, 44, 4275.

10 (a) Olivi, N.; Thomas, E.; Peyrat, J.-F.; Alami, M.; Brion, J.-D. Synlett 2004, 2175; (b) Le Bras, G.; Provot, O.; Peyrat, J.-F.; Alami, M.; Brion, J.-D. Tetrahedron Lett. 2006, 47, 5497; (c) Le Bras, G.; Hamze, A.; Messaoudi, S.; Provot, O.; Le Calvez, P. B.; Brion, J.D.; Alami, M. Synthesis 2008, 1607; (d) Jacubert, M.; Hamze, A.; Provot, O.; Peyrat, J.-F.; Brion, J.-D.; Alami, M. Tetrahedron Lett. 2009, 50, 3588 .

11 (a) For the coupling of $N$-tosylhydrazones with aryl halides or triflates, see: (a) Barluenga, J.; Moriel, P.; Valdes, C.; Aznar, F. Angew. Chem. Int. Ed. 2007, 46, 5587. (b) Barluenga, J.; TomasGamasa, M.; Moriel, P.; Amar, F.; Valdes, C. Chem. Eur. J. 2008, 14, 4792. (c) Barluenga J.; Escribano M.; Moriel P.; Aznar F.; Valdés C. Chem. Eur. J. 2009, 15, 13291. (d) Treguier, B.; Hamze, A.; Provot, O.; Brion, J. D.; Alami, M. Tetrahedron Lett. 2009, 50, 6549. (e) Brachet, E.; Hamze, A.; Peyrat, J.-F.; Brion, J.-D.; Alami, M. Org. Lett. 2010, 12, 4042. (f) Barluenga, J.; Escribano, M.; Aznar, F.; Valdés, C. Angew. Chem. Int. Ed. 2010, 49, 6856. For the coupling with benzyl halides, see: (g) Xiao, Q.; Ma, J.; Yang, Y.; Zhang, Y.; Wang, J. Org. Lett. 2009, 11, 4732. For the coupling with arylboronic acids, see: (h) Zhao, X.; Jing, J.; Lu, K.; Zhang, Y.; Wang, J. Chem. Commun. 2010, 46, 1724.

12 Jacubert, M.; Provot, O.; Peyrat, J.-F.; Hamze, A.; Brion, J.-D.; Alami, M. Tetrahedron 2010, 66, 3775

13 (a) Sonogashira, K.; Tohda, Y.; Hagihara, N. Tetrahedron Lett. 1975, 4467; (b) Alami, M.; Ferri, F.; Linstrumelle, G. Tetrahedron Lett. 1993, 34, 6403 .

14 With $\operatorname{Pd}_{2}(\mathrm{dba})_{3}$ as the catalyst, a lower yield of $\mathbf{4 a}$ was obtained $(29 \%)$

15 General procedure for the synthesis of 4. To an Emrys Optimizer $0.5-2 \mathrm{~mL}$ pyrex reaction vessel were added alkyne $(1.2 \mathrm{mmol})$ and PTSA. $\mathrm{H}_{2} \mathrm{O}(0.25 \mathrm{mmol})$ in EtOH $(1 \mathrm{~mL})$. The reaction vessel was then placed in the Emrys Optimizer and exposed to microwave irradiation according to the following specifications: temperature, $120{ }^{\circ} \mathrm{C}$; time, $30 \mathrm{~min}$; fixed hold time, on; sample absorption, high; pre-stirring, $60 \mathrm{~s}$. After cooling to room temperature, 4methylbenzenesulfonhydrazide $(1.35 \mathrm{mmol})$ was added and the reaction vessel exposed once again to microwave irradiation according to the following specifications: temperature, $50{ }^{\circ} \mathrm{C}$; time, $15 \mathrm{~min}$; fixed hold time, on; sample absorption, high; pre-stirring, 60 s. After cooling to room temperature, $\mathrm{PdCl}_{2}(\mathrm{MeCN})_{2} \quad(0.15$ $\mathrm{mmol})$, Xphos $(0.3 \mathrm{mmol})$, lithium tert-butoxide $(6.15 \mathrm{mmol})$ and dioxane $(1 \mathrm{~mL})$ were added, and the mixture was stirred at room temperature. After three minutes, the aryl halide $(1.5 \mathrm{mmol})$ was finally added, the vessel was closed and the mixture was stirred at $90{ }^{\circ} \mathrm{C}$ for $1 \mathrm{~h}$. After cooling to room temperature, $\mathrm{H}_{2} \mathrm{O}$ was added and the mixture was extracted with $\mathrm{CH}_{2} \mathrm{Cl}_{2}(3 \times 2 \mathrm{~mL})$. Organic 
layers were dried, concentrated, and the crude was purified by column chromatography on silica gel.

All the compounds gave satisfactory spectroscopic data. Data for the selected compound $\mathbf{4 b}$ are given below (Yield $=93 \%$ ). $R_{f} 0.50$ (cyclohexane/EtOAc, 9:1). ${ }^{1} \mathrm{H}$ NMR $\left(\mathrm{CDCl}_{3}, 400 \mathrm{MHz}\right): \delta 7.34$ (t, $J$ $=8.4 \mathrm{~Hz}, 1 \mathrm{H}), 7.28-7.14(\mathrm{~m}, 4 \mathrm{H}), 7.10(\mathrm{dd}, J=7.4$ and $1.7 \mathrm{~Hz}, 1 \mathrm{H})$, $6.81(\mathrm{~d}, J=8.9 \mathrm{~Hz}, 2 \mathrm{H}), 6.29(\mathrm{t}, J=6.5 \mathrm{~Hz}, 1 \mathrm{H}), 3.98-3.79(\mathrm{~m}, 2 \mathrm{H})$, $3.78(\mathrm{~s}, 3 \mathrm{H}), 3.43(\mathrm{q}, J=7.0 \mathrm{~Hz}, 2 \mathrm{H}), 2.35(\mathrm{~s}, 3 \mathrm{H}), 1.17(\mathrm{t}, J=7.0$ $\mathrm{Hz}, 3 \mathrm{H}) .{ }^{13} \mathrm{C} \mathrm{NMR}\left(\mathrm{CDCl}_{3}, 100 \mathrm{MHz}\right): \delta 159.1,140.7,138.2,137.5$, 132.4, 129.9, 128.1, 127.6 (2C), 125.5, 124.5, 124.4, 113.7 (2C), 68.5, 65.6, 55.2, 15.3 (2C). IR $\left(v^{-1}\right): 1510,1247,1181,1098$, 904, 727, 650. MS (APCI+) m/z $315.1(\mathrm{M}+\mathrm{H})^{+}$

16 Barluenga, J.; Tomás-Gamasa, M.; Aznar, F.; Valdés, C. Chem. Eur. J. 2010, 16, 12801.

17 Typical procedure for the synthesis of 4-arylchromene $3 \mathrm{~b}$. PTSA (3 equiv.) and $\mathbf{4 f}$ (1 equiv.) were refluxed in EtOH for $1 \mathrm{~h}$. After cooling to room temperature, $\mathrm{H}_{2} \mathrm{O}$ was added and the mixture was extracted with $\mathrm{CH}_{2} \mathrm{Cl}_{2}(3 \times 2 \mathrm{~mL})$. Organic layers were dried, concentrated, and the crude was purified by column chromatography on silica gel. Compound 3b (Yield $=78 \%$ ). $\quad \mathrm{R}_{\mathrm{f}} 0.75$ (cyclohexane/EtOAc, 9:1). ${ }^{1} \mathrm{H}$ NMR $\left(\mathrm{CDCl}_{3}, 300 \mathrm{MHz}\right): \delta 7.77$ (d, $J$ $=8.5 \mathrm{~Hz}, 2 \mathrm{H}), 7.34-7.06(\mathrm{~m}, 6 \mathrm{H}), 6.88(\mathrm{~d}, J=8.8 \mathrm{~Hz}, 2 \mathrm{H}), 5.96(\mathrm{t}$, $J=4.9 \mathrm{~Hz}, 1 \mathrm{H}), 4.68(\mathrm{~d}, J=4.9 \mathrm{~Hz}, 2 \mathrm{H}), 3.84(\mathrm{~s}, 3 \mathrm{H}) .{ }^{13} \mathrm{C} \mathrm{NMR}$ $\left(\mathrm{CDCl}_{3}, 75 \mathrm{MHz}\right): \delta$ 159.0, 155.1, 137.6, 133.6, 130.35, 130.3, 130.1, 128.8 (2C), 128.4, 126.6, 125.2, 123.3, 119.1, 117.75, 117.7, 113.8 (2C), 64.5, 55.3. IR $\left(v^{-1} \mathrm{~cm}^{-1}\right): 1658,1596,1509,1462,1246$, 1226, 1143, 1099, 1029, 994, 907, 837, 803, 781, 749, 728, 648, 615. MS (APCI+) m/z $289.0(\mathrm{M}+\mathrm{H})^{+}$. 